\title{
Presentación de un óleo inédito sobre la Conquista de México
}

or medio de la directora del Centro Nacional de Conservación y
Registro del Patrimonio Artístico Mueble, Lucía García Noriega, cono-
cí una interesante pintura al óleo recientemente restaurada con el tema de la Conquista de México. La obra, mediante una secuencia de números, sigue uno a uno los episodios de esa etapa, donde abundan particularmente las batallas de los españoles contra los indígenas en el valle de México. Un tratamiento análogo de una epopeya visual con este asunto, inusual para una pintura al óleo, está presente en dos muy conocidos biombos pintados al óleo: el que alberga el Museo de Historia del Castillo de Chapultepec y el que se encuentra en el Museo Franz Mayer. El mismo tema lo abordaron a menudo los biombos de enconchados, como el que exhibe el Museo Nacional del Virreinato en Tepotzotlán o las series de la Conquista resguardadas en el Museo de América de Madrid y en el Museo Nacional de Bellas Artes de Buenos Aires.

Lo que salta a la vista como particularmente interesante y original en el óleo sobre la Conquista recién restaurado que aquí se comenta es, junto a la representación narrativa hilvanada en diversos episodios, un intento de figuración espacial de la vieja Tenochtitlán que remite a los mapas renacentistas de esta ciudad, como el que ilustra la edición latina de las Cartas de relación de Hernán Cortés publicada en Nuremberg en $1524,{ }^{2}$ el de Benedetto Bordone, que repre-

I. Elisa Vargaslugo, "La pintura de enconchados", en México en el mundo de las colecciones de arte, México, Grupo Azabache, 1994.

2. Fernando Benítez, Historia de la ciudad de México, México, Salvat, I983, vol. II, pp. 38-39. 


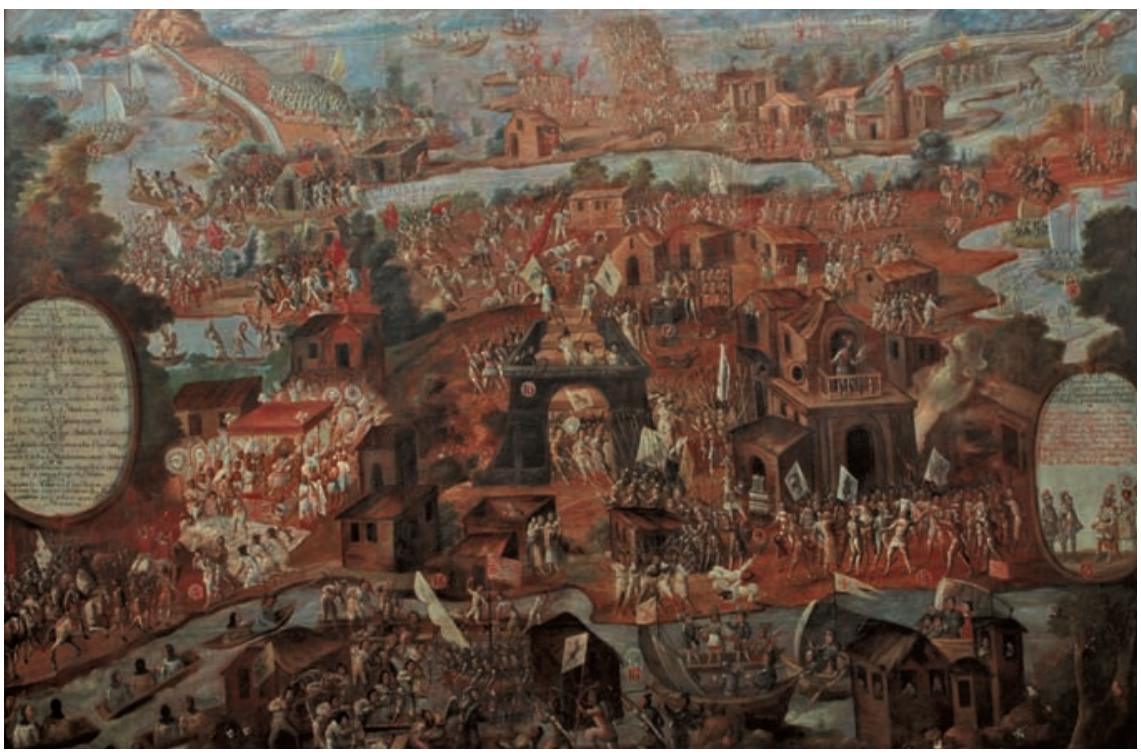

I. Juan Asencio, La Conquista de México, Nueva España, finales del siglo xvıI, óleo sobre tela, 2.16 ×3.1 I m, sin marco. Conservaduría del Palacio Nacional de México.

senta Tenochtitlán como una isla a la que incluye en su Insularum de $1528,{ }^{3} \mathrm{O}$ el que ofrece Juan Bautista Ramusio en su Colección de viajes. ${ }^{4}$ En estos mapas, la capital mexicana está rodeada de agua y su centro es presidido por el cuerpo piramidal del Templo Mayor. Lo mismo ocurre en el óleo de la Conquista aquí referido, donde la calzada de Guadalupe, ocupada por bergantines, bordea la esquina superior izquierda de tierra firme, mientras que Chapultepec, con su lago erizado también por las hirsutas lanzas de las naves españolas, enmarca la esquina superior derecha. En la parte inferior del cuadro encontramos otro brazo de agua que rodea la tierra firme y donde se escenifican batallas navales y la aprehensión de Cuauhtémoc en su canoa. Quizá a un intento de figurar el viejo albarradón de Netzahualcóyotl, realizado en la parte superior del óleo, se debe la franja horizontal de tierra rodeada de agua.

La tierra firme, en el óleo comentado, está prácticamente envuelta por agua por los cuatro lados. También en el centro del territorio, como en los mapas mencionados, esta pintura nos muestra como lugar que organiza el espacio cir-

3. Ibidem, p. 4I.

4. Ibidem, pp. 42-43. 


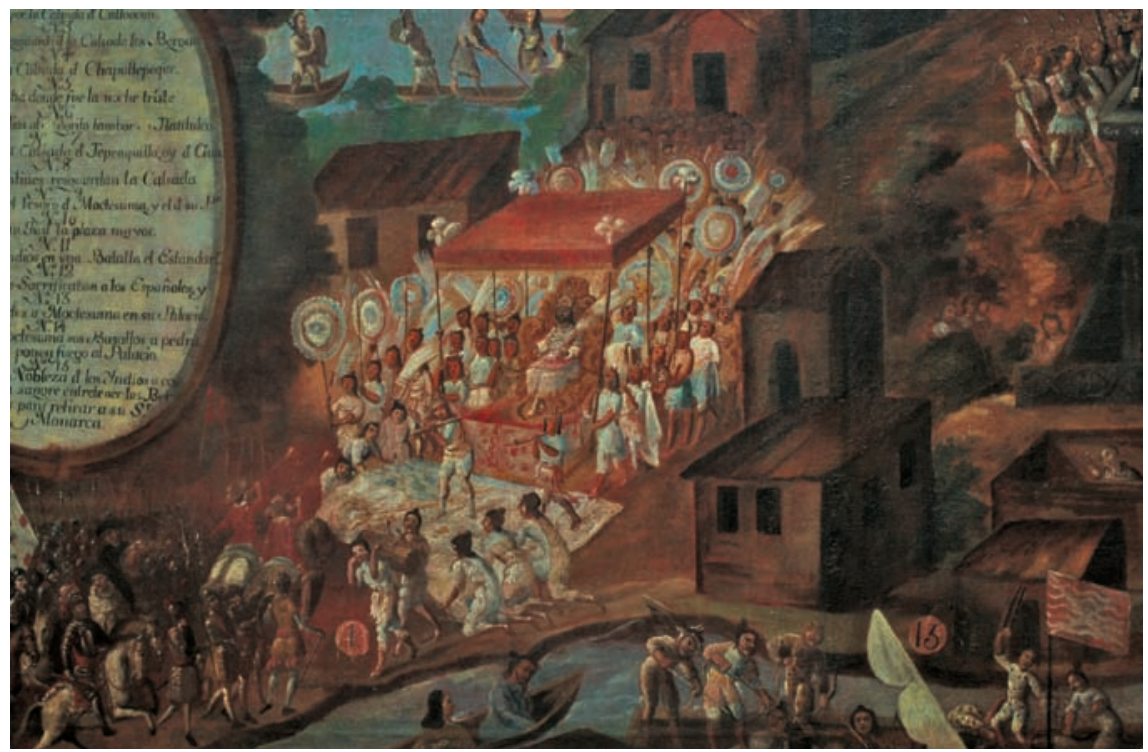

2. Juan Asencio, La Conquista de México, detalle, Nueva España, finales del siglo Xviı, óleo sobre tela, 2.16 × 3. I I m, sin marco. Conservaduría del Palacio Nacional de México.

cundante a la imagen del templo. La manera en que se figuró el templo nos recuerda mucho el biombo del Museo de Historia de Chapultepec, obra quizá anterior a la que aquí presentamos. Debe agregarse que, en el biombo del Museo del Castillo de Chapultepec, el templo no ocupa la parte central de la representación y que, de hecho, los episodios, en ambos trabajos, siguen un ordenamiento en el espacio muy distinto. En este óleo de la Conquista tendríamos, por lo tanto, una idea de Tenochtitlán, a la vez geográfica e histórica: la tierra mexicana se compone no sólo de tierra y lagos, sino también de conflictos y batallas. A su vez, la trabazón sangrienta entre dos razas teje simbólicamente el territorio material.

El óleo de la Conquista — de $2.16 \times 3.11 \mathrm{~m}$ - se encontró en muy malas condiciones en las bodegas del Palacio Nacional. Las restauradoras Laura Flores y Ruth Harquín realizaron la limpieza, desmontaje, reentelado, resane y un importante trabajo de reintegración en amplias zonas antes dañadas. La soltura de la pincelada recuerda — aunque muy lejos de su calidad— la de Cristóbal de Villalpando e induce a ubicar la obra a finales del siglo XviI novohispano. Este periodo parece ser ratificado por una firma con data en la zona central, pinta- 


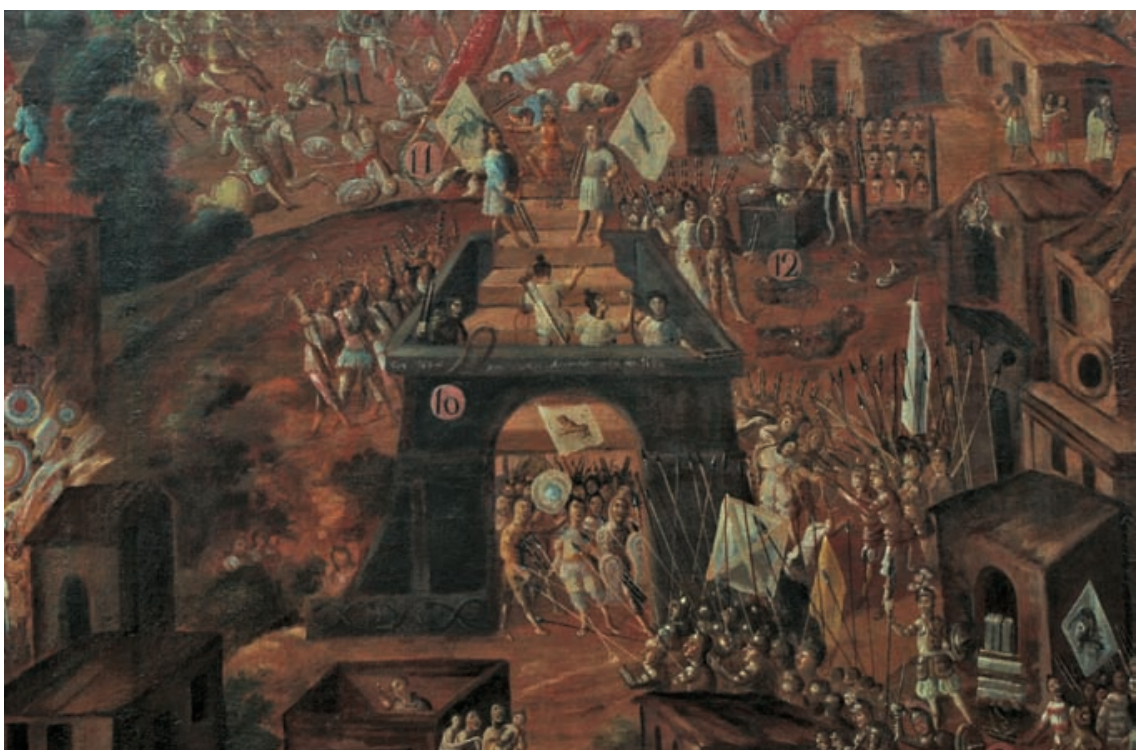

3. Juan Asencio, La Conquista de México, detalle, Nueva España, finales del siglo Xvı, óleo sobre tela, 2.16 × 3.I I m, sin marco. Conservaduría del Palacio Nacional de México.

da en color blanco, sobre el borde frontal del templo central de Tenochtitlán, que reza: "En Mexico por Juan Asencio [...ne] I683".

Sin embargo, es evidente, por las dos cartelas rococó ornamentadas con motivos de rocalla situadas a izquierda y derecha del óleo, que este cuadro experimentó una importante intervención en el siglo XviII, pues las cartelas no pueden ser más que posteriores. De hecho, aparece una segunda firma que así lo indica: "Miguel Guzman [?] lo retocó". En distintos lugares del cuadro se traslucen, bajo una capa de pintura posterior, los rasgos de los que fueron los números de una secuencia anterior, sustituidos luego por una nueva numeración y ordenación de las escenas.

La primera cartela muestra con letras negras la siguiente lista de escenas, que somos invitados a identificar en el cuadro:

N. I Primera entrada de Cortes por la Calsada de San Antonio donde lo resivio Moctesuma.

N. 2 Entrada por la Calzada de Culloacan.

N. 3 Pelean en resguardo de la Calsada los Bergantines. 


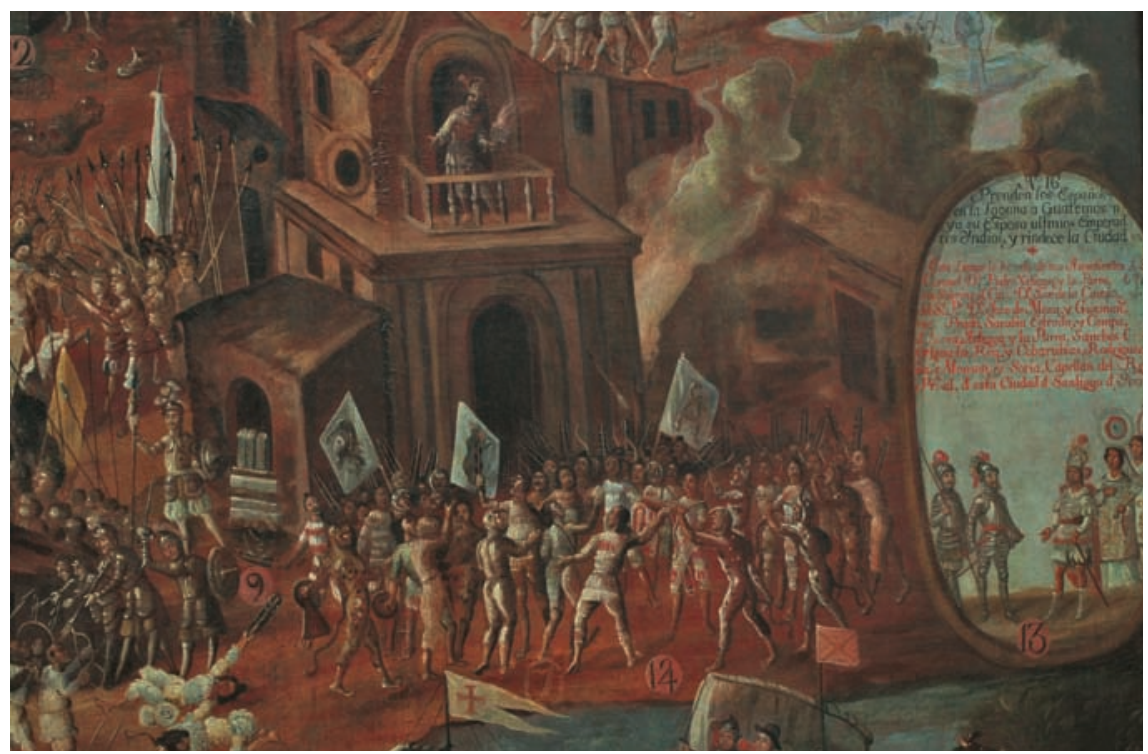

4. Juan Asencio, La Conquista de México, detalle, Nueva España, finales del siglo Xviı, óleo sobre tela, 2.16×3.I I m, sin marco. Conservaduría del Palacio Nacional de México.

N. 4 Entrada por la Calsada de Chapultepec.

N. 5 Calsada Tacuba donde fue la noche triste.

N. 6 Azotan los Yndios al Negrito Tambor en Tlatilulco.

N. 7 Entrada [?] por la Calsada de Tepeaquilla y de Guadalupe.

N. 8 Los Bergantines resguardan la Calsada.

N. 9 Abre Cortés el tesoro de Moctesuma y el de su pueblo.

N. ıo El Govierno de la plaza mayor.

N. I I Roban [?] los Yndios en una Batalla el Estandarte Real.

N. I2 Piedra donde Sacrificaban a los Espańoles y a los Caballos.

N. I3 Prende Cortés a Moctesuma en su Palacio.

N. I4 Matan a Moctesuma sus Basallos a pedradas y ponen fuego al Palacio.

N. I5 Procura la Nobleza de los Yndios a costa de mucha sangre entretener los Bergantines para retirar a su Señor Monarca.

La segunda cartela, situada a la derecha del óleo, brinda con letras negras la siguiente información: "N.ı6 Prenden los Españoles en Laguna a Cuautemosen y a su Esposa, últimos Emperadores Yndios, y rindece la ciudad". 


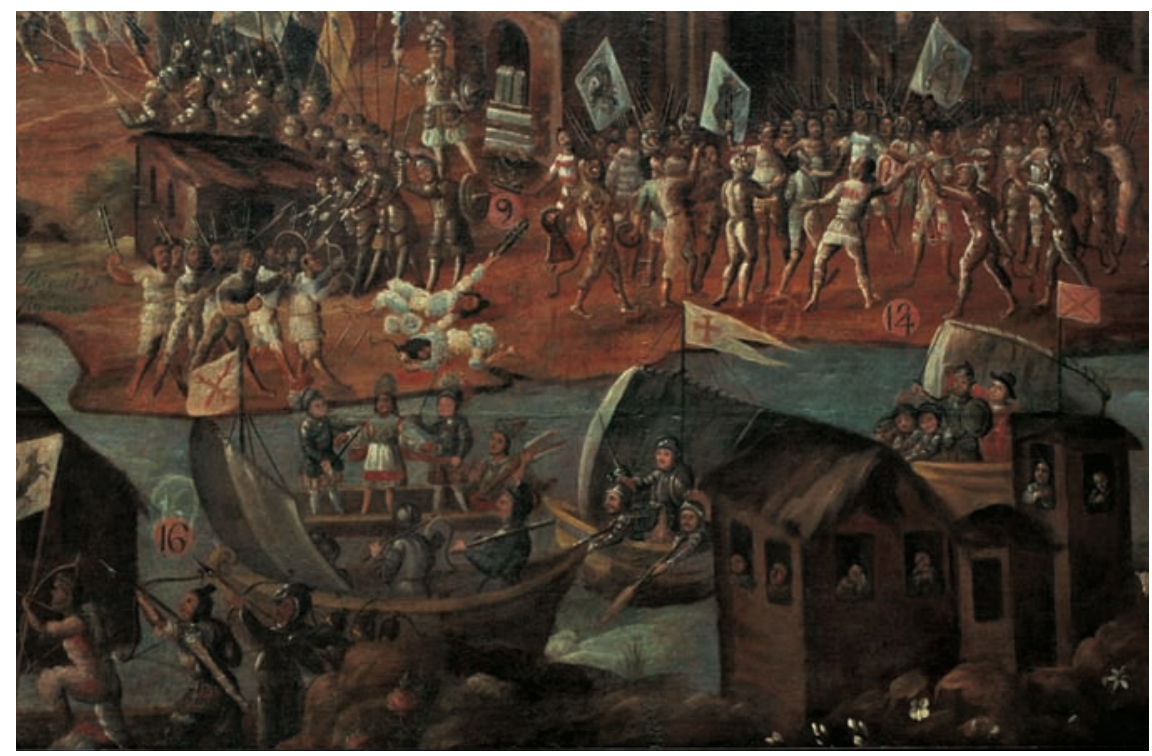

5. Juan Asencio, La Conquista de México, detalle, Nueva España, finales del siglo Xvı, óleo sobre tela, 2.16 × 3.I I m, sin marco. Conservaduría del Palacio Nacional de México.

Abajo de las letras negras aparece otra leyenda en letras rojas que, por desgracia, se halla incompleta debido a dańos que ha sufrido el lienzo. Sin embargo, las restauradoras restituyeron los faltantes con pintura clara:

Este Lienso lo heredó de sus Ascendientes el Señor Coronel Don Pedro Urtiaga y la Parra [...] Señor su sobrino del Capitan Don José de la Campa y [...] del Señor Presbitero Don José de la Meza y Guzman, [...rez] Prado, Sarabia Estrada, y Campa, [...] de A...ra, Arteaga y la Parra, Sanchez [c...] Ortega La Rea y Cobarubias, Rodríguez Ocaña Monson y Soria, Capellan del Regimiento de esta Ciudad de Santiago de Queretaro.

Muchas incógnitas sobre la historia de esta pintura y la razón de sus distintos cambios de paradero despierta esta segunda cartela, y para responderlas se requeriría una investigación profunda. Pero en esta breve presentación convendría destacar algunos rasgos de enorme encanto e interés de la pintura, como la representación de los Caballeros Águila como si fueran arcángeles del cielo y la mágica figuración de un caballero que flota sobre la techumbre del Palacio de 
Moctezuma, la cual remite muy probablemente a Santiago Matamoros, al que algunos soldados veían como una aparición de buen augurio. También es asombrosa la representación del tzompantli con cabezas tanto humanas como equinas y el descuartizamiento de los caballos en el suelo. Llama a su vez la atención la probable figuración del dios Quetzalcóatl como si fuera un hombre sentado que sostiene el caduceo de Mercurio en una mano. Sorprende por igual el hecho de que una de las escenas, la "N. I3 Prende Cortés a Moctezuma”, se encuentra representada en el interior de la segunda cartela, aislada del restante espacio exterior. \& 